\title{
FTY720 (fingolimod) modulates the severity of viral-induced encephalomyelitis and demyelination
}

\author{
Caroline A Blanc ${ }^{1}$, Hugh Rosen ${ }^{2}$ and Thomas E Lane ${ }^{3^{*}}$
}

\begin{abstract}
Background: FTY720 (fingolimod) is the first oral drug approved by the Food and Drug Administration for treatment of patients with the relapsing-remitting form of the human demyelinating disease multiple sclerosis. Evidence suggests that the therapeutic benefit of FTY720 occurs by preventing the egress of lymphocytes from lymph nodes thereby inhibiting the infiltration of disease-causing lymphocytes into the central nervous system (CNS). We hypothesized that FTY720 treatment would affect lymphocyte migration to the CNS and influence disease severity in a mouse model of viral-induced neurologic disease.

Methods: Mice were infected intracranially with the neurotropic JHM strain of mouse hepatitis virus. Infected animals were treated with increasing doses $(1,3$ and $10 \mathrm{mg} / \mathrm{kg}$ ) of FTY720 and morbidity and mortality recorded. Infiltration of inflammatory virus-specific T cells (tetramer staining) into the CNS of FTY720-treated mice was determined using flow cytometry. The effects of FTY720 treatment on virus-specific T cell proliferation, cytokine production and cytolytic activity were also determined. The severity of neuroinflammation and demyelination in FTY720-treated mice was examined by flow cytometry and histopathologically, respectively, in the spinal cords of the mice.

Results: Administration of FTY720 to JHMV-infected mice resulted in increased clinical disease severity and mortality. These results correlated with impaired ability to control viral replication $(P<0.05)$ within the CNS at days 7 and 14 post-infection, which was associated with diminished accumulation of virus-specific CD4+ and CD8+ T cells $(P<0.05)$ into the CNS. Reduced neuroinflammation in FTY720-treated mice correlated with increased retention of T lymphocytes within draining cervical lymph nodes $(P<0.05)$. Treatment with FTY720 did not affect virus-specific $T$ cell proliferation, expression of IFN- $\gamma$, TNF-a or cytolytic activity. FTY720-treated mice exhibited a reduction in the severity of demyelination associated with dampened neuroinflammation.
\end{abstract}

Conclusion: These findings indicate that FTY720 mutes effective anti-viral immune responses through impacting migration and accumulation of virus-specific T cells within the CNS during acute viral-induced encephalomyelitis. FTY720 treatment reduces the severity of neuroinflammatory-mediated demyelination by restricting the access of disease-causing lymphocytes into the CNS but is not associated with viral recrudescence in this model.

Keywords: FTY720, S1P receptor, virus, central nervous system, T lymphocytes, demyelination

\section{Background}

Multiple sclerosis (MS) is a neurodegenerative inflammatory disease of the central nervous system (CNS), which leads to demyelination and progressive neurological disability [1,2]. FTY720, also called Gilenya/fingolimod, is an oral drug recently approved by the Food and Drug Administration (FDA) for treatment of patients with the relapsing-remitting form of MS [3-8]. FTY720 is an

\footnotetext{
* Correspondence: tom.lane@path.utah.edu

${ }^{3}$ Department of Pathology, Division of Microbiology \& Immunology, University of Utah School of Medicine, Salt Lake City, Utah 84112, USA Full list of author information is available at the end of the article
}

immunomodulatory drug that has shown to reduce both acute relapses but also new lesion formation as well as disability progression and brain volume loss in MS patients [9]. The mechanisms for how FTY720 functions are not yet defined; however, the phosphorylated active form of FTY720 (FTY720P) is a sphingosine-1-phosphate (S1P) receptor modulator that inhibits egress of lymphocytes from lymph nodes [9-11]. It is thought that this leads to a dampening of autoreactive $\mathrm{T}$ cells specific for myelin antigens infiltrating into the CNS. Importantly, FTY720, due to its lipophilic nature, penetrates the 
blood-brain-barrier and readily enters the CNS parenchyma [9]. Furthermore, FTY720P is detected in situ, suggesting that it may influence the biology of resident cells of the CNS [9].

FTY720 has been shown to improve disease severity in experimental autoimmune encephalomyelitis (EAE), an autoimmune model of neuroinflammation and demyelination commonly used as a model for MS [12-14]. Indeed, therapeutic administration of FTY720 in EAE models is associated with reduced neuroinflammation and improved motor skills [12-15]. In addition to EAE, viral models of demyelination are also relevant tools for studying the pathogenesis of neuroinflammatory-mediated demyelination. For example, infection of susceptible mice with the neurotropic JHM strain of mouse hepatitis virus (JHMV) results in an acute encephalomyelitis followed by chronic demyelination. Like MS, components of the immune system, such as T cells and macrophages, are important contributors to white matter destruction [16-18]. Moreover, JHMV-infected mice undergoing chronic demyelination show similar clinical and histologic disease profiles compared to MS patients [19-21]. As viruses are considered to be a contributing cause of MS [22-35], JHMV infection of the CNS offers not only an excellent model for studying the immunopathological mechanism driving demyelination in MS patients but also can provide insight into effects of MS therapeutics within the context of viralinduced demyelination. We have evaluated the effects of FTY720 on both host defense and disease progression in JHMV-infected mice. Our findings reveal that FTY720 treatment resulted in increased mortality associated with impaired ability to control viral replication. FTY720 did not alter anti-viral effects of $\mathrm{T}$ cells, e.g. cytokine secretion or cytolytic activity, but affected lymphocyte egress from draining cervical lymph nodes and accumulation of virus-specific T cells within the CNS. Therefore, FTY720 treatment mutes effective anti-viral immune responses following infection with a neurotropic virus by dampening trafficking of virus-specific T cells to the CNS. Conversely, administration of FTY720 to JHMV-infected mice reduced the severity of demyelination by limiting infiltration of inflammatory $\mathrm{T}$ cells into the CNS.

\section{Methods}

\section{Virus and mice}

Age-matched (5 to 7 weeks) S1P1 eGFP knock-in mice (C57BL/6 background) [36] and C57BL/6 mice were anesthetized with an intra-peritoneal (i.p.) injection of $150 \mu \mathrm{l}$ of a mixture of ketamine (Western Medical Supply, Arcadia, CA, USA) and xylazine (Phoenix Pharmaceutical, Saint Joseph, MO, USA) in Hank's balanced salt solution. Mice were injected intra-cranially (i.c.) with 150 plaque forming units (PFU) of JHMV (strain V2.2-1) suspended in $30 \mu \mathrm{l}$ saline [37]. Clinical severity was assessed using a previously described four-point scoring scale [16]. FTY720 (2-amino-2- [2-(4-octylphenyl) ethyl]-1,3-propanediol, hydrochloride) and FTY720P (2-amino-2[2-(4-octylphenyl) ethyl]-1,3-propanediol, mono dihydrogen phosphate ester) were purchased from Cayman Chemical Co (Ann Arbor, MI, USA). Administration of FTY720 or the vehicle was performed by daily i.p. injections of $100 \mu \mathrm{l}$ starting at day 5 post-infection (p.i.). For analysis of viral titers, mice were sacrificed at defined time points. One half of each brain was removed as well as spinal cords. These were homogenized and used in a plaque assay performed using DBT mouse astrocytoma cell line [38]. Experiments for all animal studies were reviewed and approved by the University of Utah and the University of California, Irvine Institutional Animal Care and Use Committee.

\section{Cell isolation and flow cytometry}

Immunophenotyping of the cellular infiltrate present within cervical lymph nodes, brains and spinal cords of infected mice was accomplished by homogenizing isolated tissue and generating a single-cell suspension for analysis by flow cytometry as previously described [39-41]. In brief, isolated cells were Fc blocked with anti-CD16/32 1:200. The following antibodies were used for immunophenotyping: APC-conjugated rat anti-mouse B220 for B cells; APC-conjugated rat anti-mouse CD4 for CD4+ T cells; PE-conjugated rat anti-mouse CD8 and APC-conjugated rat anti-mouse CD8 for CD8+ T cells; PE-conjugated rat anti-mouse interferon-gamma (IFN- $\gamma$ ) for intracellular cytokine staining; PE-Cy7-conjugated rat anti-mouse CD45, APC-conjugated rat anti-mouse CD19 and PE-conjugated rat anti-mouse CD138 for antibody secreting cells; M133-147 tetramer-PE for virus specific CD4+ T cells and S510-518 tetramer-PE for virus-specific CD8+ T cells. Cell isolates for IFN- $\gamma$ intracellular staining were cultured in $200 \mu \mathrm{l}$ RPMI-1640 supplemented with $10 \%$ fetal bovine serum, L-glutamine and penicillinstreptomycin, and stimulated ex vivo with the immunodominant CD4 epitope (M133-147) or the immunodominant CD8 (S510-518) and Golgi stop for $6 \mathrm{~h}$ followed by intracellular staining $[42,43]$. The cells were then fixed and permeabilized by using a BD cytofix/cytoperm plus kit and then stained for intracellular IFN- $\gamma$ for $30 \mathrm{~min}$ at $4^{\circ} \mathrm{C}$ [44]. Immunophenotyping of lymphocytes was performed following red blood cell lysis on blood samples collected with heparin-coated syringes by heart puncture from S1P1 eGFP knock-in mice. Cells were then Fc blocked with anti-CD16/32 1:200 and stained with PE-conjugated rat anti-mouse CD3. Samples were then analyzed on a BD LSR II flow cytometer.

\section{Proliferation assay}

Splenocytes were isolated from mice at day 8 following i.p. infection with $2.5 \times 10^{5}$ PFU of the DM strain of 
mouse hepatitis virus (MHV-DM). Enriched populations of CD4+ and CD8+ T cells, isolated according to the manufacturer's instructions (CD4 and CD8 Isolation kits, Miltenyi Biotec, Auburn, CA, USA), were labeled with the fluorescent dye, carboxyfluorescein diacetate succinimidyl ester (CFSE) (Life Technologies, Grand Island, NY, USA), at $2.5 \mu \mathrm{M}$ final concentration. Then $1 \times 10^{6}$ total cells per well were incubated with FTY720P $100 \mathrm{nM}$ or vehicle and stimulated with $5 \mu \mathrm{M}$ final peptide concentration of CD4+ T cell immunodominant epitope M133-147, CD8+ T cell immunodominant epitope S510518 , or non-specific OVA control, and cultured for $72 \mathrm{~h}$ at $37^{\circ} \mathrm{C}, 5 \% \mathrm{CO}_{2}$ in complete media. Cells were then washed and the Fc receptor blocked with $1 \times \mathrm{PBS}$ containing $1 \%$ BSA and a 1:200 dilution of rat anti-mouse CD16/32 antibody (Pharmingen, San Jose, CA, USA). Next, cells were stained for surface antigens using APCconjugated rat anti-mouse CD4 and CD8 (Pharmingen, San Jose, CA, USA), according to the viral peptide stimulation condition, for $45 \mathrm{~min}$ at $4^{\circ} \mathrm{C}$. Cells were analyzed and the data assessed as described above.

\section{Cytotoxic T lymphocyte assay}

Spleen-derived CD8+ T cells were analyzed for lytic activity at day 8 following i.p. infection of C57BL/6 mice with
$2.5 \times 10^{5}$ PFU of MHV-DM. A CD8 $+\mathrm{T}$ cell-enriched population of cells was obtained via negative selection through use of a magnetically labeled antibody specific for the CD8 antigen followed by passage over a magnetic column (Miltenyi Biotec, Auburn, CA, USA) [45]. The numbers of S510-518-specific CD8+ T cells were determined by tetramer staining and these cells were used as the effector population. RMA-S cells, a murine lymphoma cell line that presents viral peptides to cytotoxic T lymphocytes (CTL), were cultured at a density of 10,000 per well in flat-bottomed 96-well format tissue culture plate (Corning Life Sciences, Tewksbury, MA, USA) and pulsed overnight with $5 \mu \mathrm{M}$ of the immunodominant CD8 peptide specific for MHV spike (S) glycoprotein, spanning amino acids 510 to 518 (S510-518, Bio-Synthesis, Lewisville, TX, USA). CD8 T-cells, exposed to either FTY720P (100 nM) or vehicle alone, were then plated with RMA-S cells at effector-to-target (E:T) ratios ranging from 20:1 to 2.5:1. Co-cultures were incubated for $4 \mathrm{~h}$ at $37^{\circ} \mathrm{C}$ in $5 \% \mathrm{CO}_{2}$ at a final volume of $200 \mu \mathrm{l}$ per well. The amounts of lactate dehydrogenase (LDH) released from lysed cells were determined using a CytoTox 96 Non-Radioactive Cytotoxicity Assay (Promega, Madison, WI, USA). The percentage of CTL-mediated lysis was determined as specified by the manufacturer's protocols.
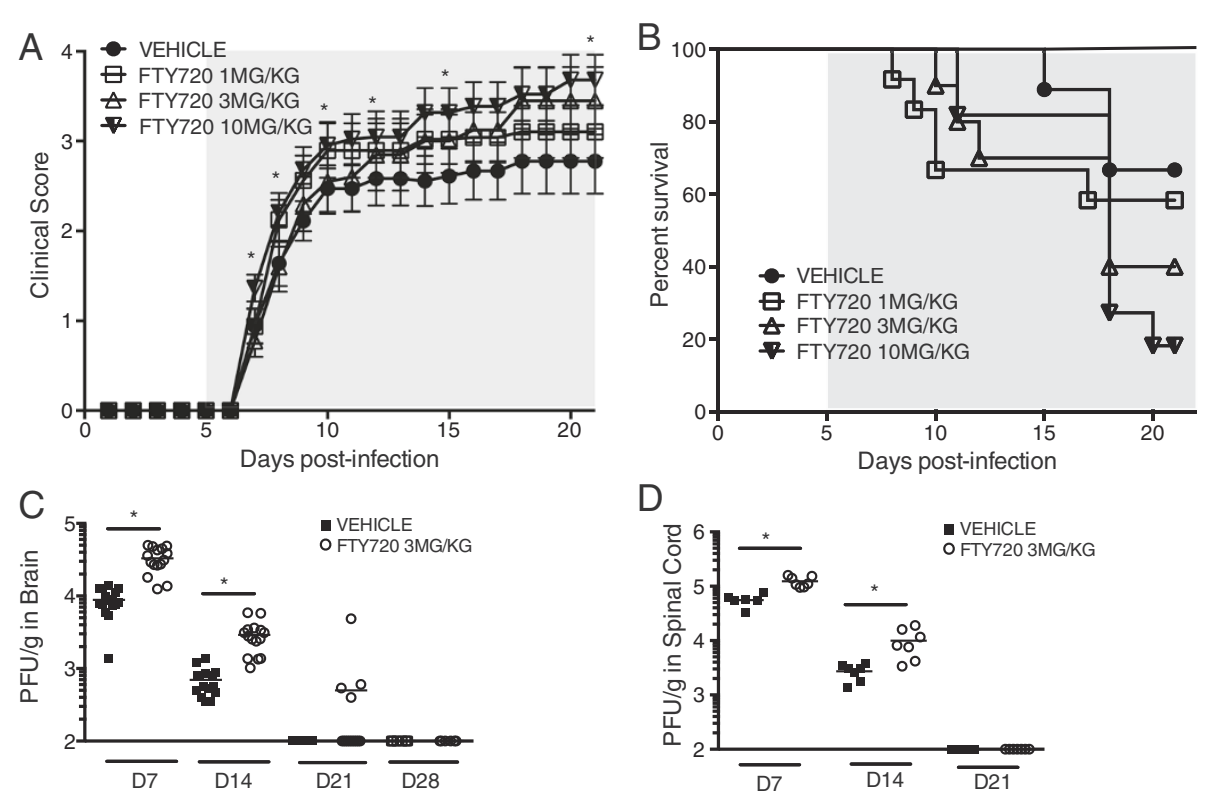

Figure 1 FTY720 treatment increases clinical disease severity, mortality and affects viral clearance from the CNS. (A) S1P1 eGFP knock-in mice C57BL/6 were infected i.c. with JHMV (150 PFU) and treated daily beginning at day 5 p.i. (shaded area) with either FTY720 (1, 3 and 10 mg/kg, $n=10$ per group) or vehicle control by i.p. injection. Infected mice showed increased clinical disease severity at all FTY720 concentrations used with $10 \mathrm{mg} / \mathrm{ml}\left({ }^{*} P<0.05\right)$ having the greatest effect compared to vehicle-treated control mice. Data are presented as average \pm standard error of the mean (SEM) and represent a minimum of two independent experiments with a minimum of five mice/group. (B) FTY720 treatment (beginning at day 5 p.i., shaded area) results in a dose-dependent increase in mortality compared to vehicle-treated mice. Data are representative of two independent experiments with a minimum of five mice/experimental group. Viral titers within the brain (C) and spinal cord (D) in JHMV-infected mice treated with either FTY720 (3 mg/kg) or vehicle (beginning at day 5 p.i.) were determined at days 7, 14 and 21 p.i. Data points represent individual mice and bars indicate averages. CNS viral titers represent two independent experiments. ${ }^{*} P<0.05$. 


\section{Cytokine production}

Spleen-derived CD4+ and CD8+ T cells from MHV-DM infected mice [39] were analyzed for cytokine secretion. CD4+ and CD8+ T cells were isolated as described above using an isolation kit according to the manufacturer's instructions (Miltenyi Biotec, Auburn, CA, USA). Then $1 \times 10^{6} \mathrm{~T}$ cells per well on a round bottom 96-well plate were incubated for $48 \mathrm{~h}$ at $37^{\circ} \mathrm{C}$ in $5 \% \mathrm{CO}_{2}$ in the presence of FTY720P $100 \mathrm{nM}$ or vehicle. Supernatants were then collected and an ELISA was performed for the following cytokines: IFN- $\gamma$ and tumor necrosis factor alpha (TNF- $\alpha$ ). Samples were run in triplicate in accordance with the manufacturer's directions (R\&D Systems, Minneapolis, MN, USA).

\section{Histology}

Clinical severity was assessed using a previously described four-point scoring scale [16]. Spinal cords were isolated at defined time points and fixed overnight with $4 \%$ paraformaldehyde at $4^{\circ} \mathrm{C}$. Spinal cords were separated into 12 coronal sections, cryoprotected in $20 \%$ sucrose and embedded in optimum cutting temperature (O.C.T) formulation (VWR, Radnor, PA, USA) [46]. Next 8- $\mu \mathrm{m}$ thick coronal sections were cut and sections were stained with luxol fast blue (LFB). Areas of total white matter and demyelinated white matter were determined with Image J Software. Demyelination was scored as a percentage of total demyelination along the entire length of the spinal cord.

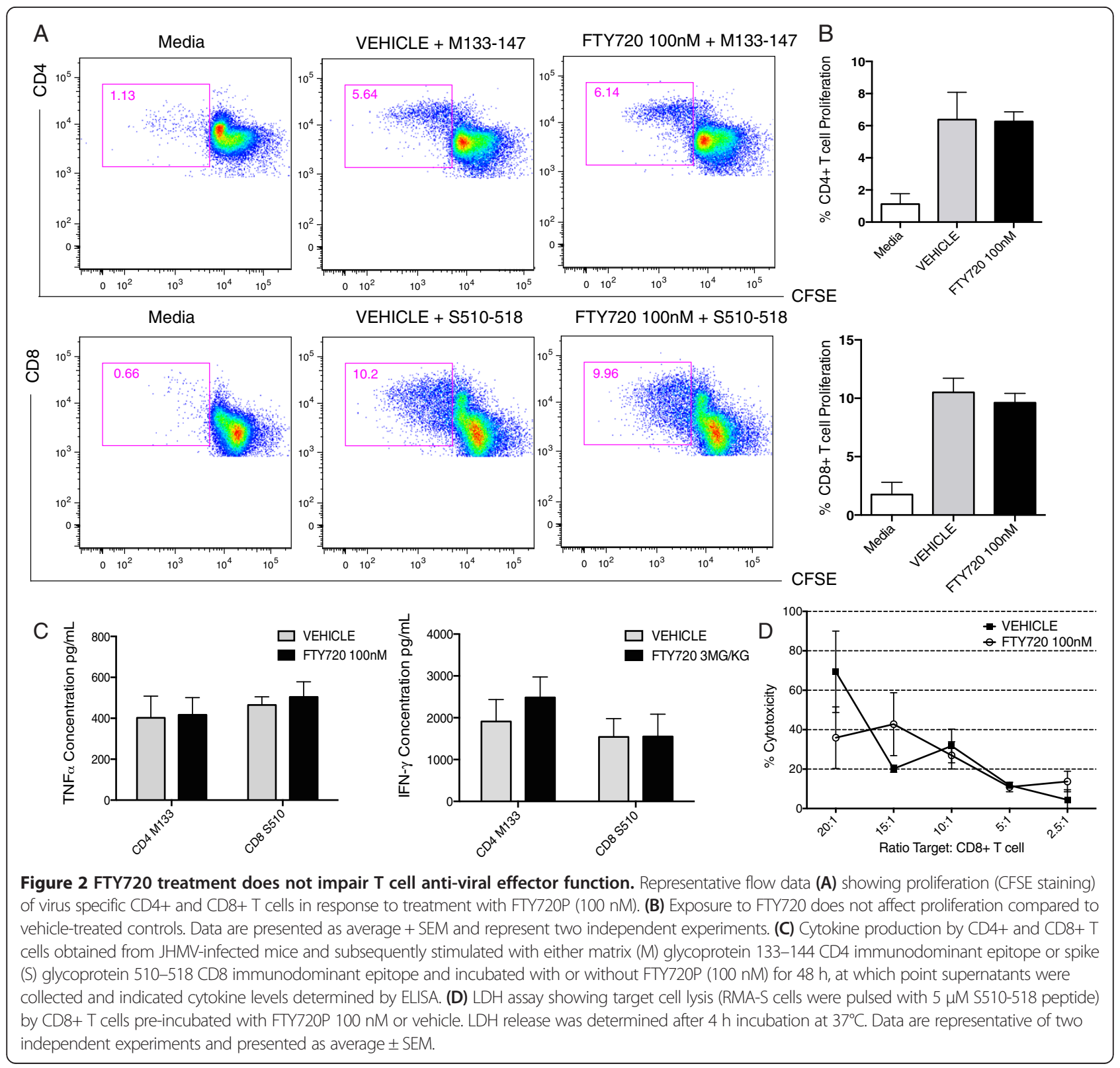


An H\&E stain was performed to determine the extent of inflammation. Spinal cord sections were scored using a four-point scale to assess neuroinflammation [16].

\section{Results}

FTY720 treatment of JHMV-infected mice increases clinical disease severity and impairs control of viral replication S1P1 eGFP knock-in mice C57BL/6 mice [36] were infected i.c. with JHMV (150 PFU) and subsequently treated with increasing concentrations $(1,3$ or $10 \mathrm{mg} / \mathrm{kg}$ ) of FTY720 via i.p. injection administered daily starting at day 5 p.i. Mice were scored daily until day 21 p.i. FTY720 treatment resulted in increased severity of clinical disease with the greatest effects occurring at $3 \mathrm{mg} / \mathrm{kg}$ and $10 \mathrm{mg} / \mathrm{kg}$ doses $(P<0.05)$ compared to vehicle-treated mice (Figure $1 \mathrm{~A})$. In accordance with clinical data, FTY720-treated mice exhibited increased mortality in a dose-dependent manner (Figure 1B). By day 21 p.i., $<30 \%$ of mice treated with $10 \mathrm{mg} / \mathrm{kg}$ FTY720 survived while mice treated with either $3 \mathrm{mg} / \mathrm{kg}$ or $1 \mathrm{mg} / \mathrm{kg}$ exhibited $40 \%$ and approximately $60 \%$ survival, respectively (Figure 1B). Based on the morbidity and mortality data, $3 \mathrm{mg} / \mathrm{kg}$ FTY720 was used for subsequent in vivo studies. FTY720 treatment resulted in increased viral burden within the brain and spinal cord as determined by plaque titer at days 7 and 14 p.i. $(P \leq 0.05)$ compared to vehicle-treated control mice (Figure 1C,D). However, at later times p.i. the majority of mice treated with FTY720 had reduced viral titers below the level of detection (approximately $100 \mathrm{PFU} / \mathrm{g}$ ) within the brain and spinal cord (Figure 1C,D). These findings indicated that the increase in mortality following administration of FTY720 correlated with impaired ability to control viral replication within the CNS and argues that either trafficking of virus-specific lymphocytes is impaired and/or anti-viral effector functions are negatively affected.

\section{T cell anti-viral effector function and FTY720 treatment}

$\mathrm{T}$ cell responses, including proliferation, secretion of IFN- $\gamma$ and CTL activity, are critical in controlling JHMV replication within the CNS [47-53]. FTY720P treatment (100 nM) had no appreciable effect on dampening proliferation of either CD8+ T cells specific for the immunodominant epitope for the spike (S) glycoprotein spanning amino acid residues 510-518 (S510-518) [42] or CD4+ T cells recognizing the matrix $(\mathrm{M})$ glycoprotein peptide 133147 (M133-147) [43] (Figure 2A,B). Lymphocytes were

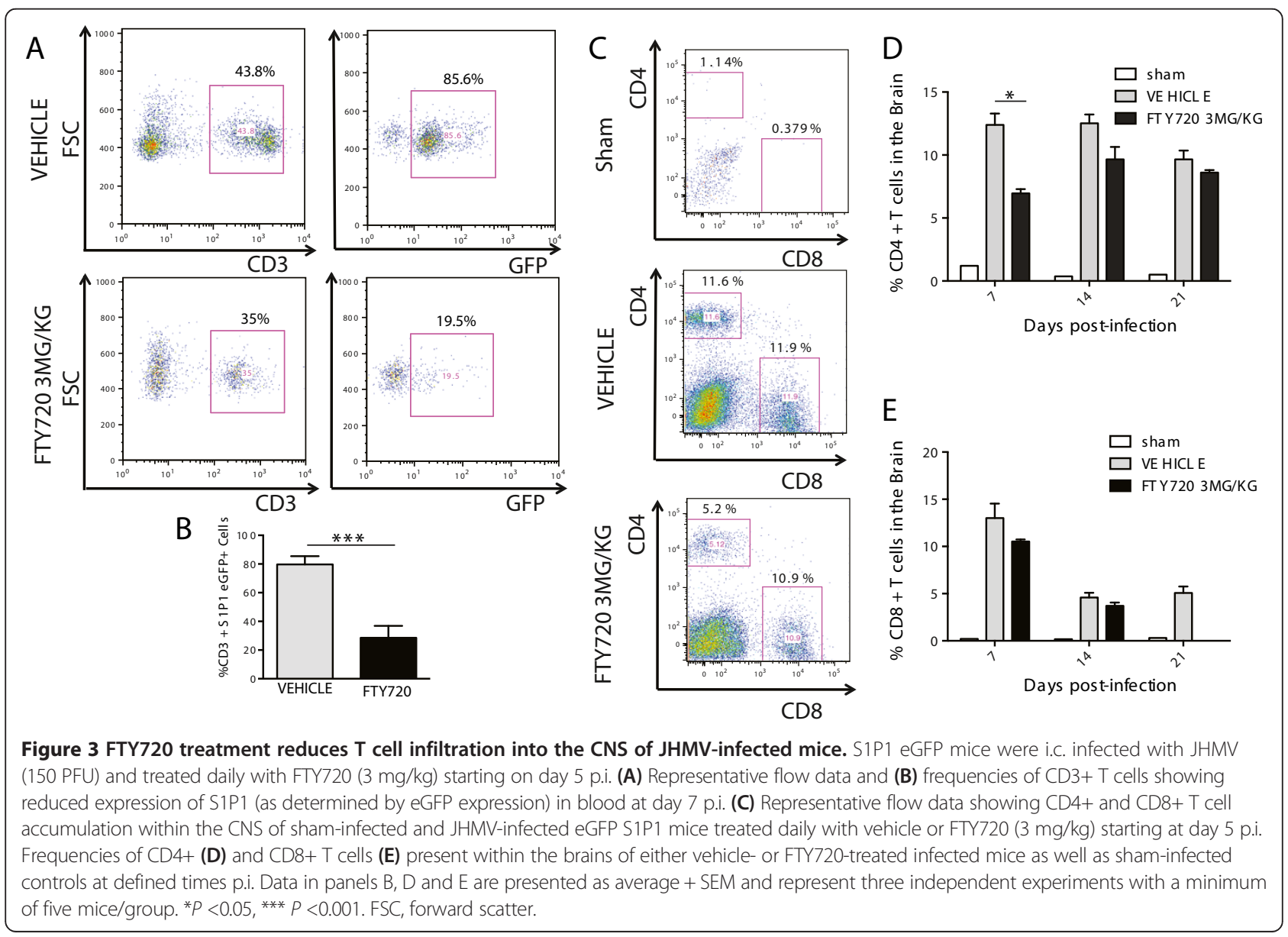


isolated from spleens of JHMV-DM infected mice day 8 p.i., pulsed with either M133-147 or S510-518 peptides and treated with FTY720P $(100 \mathrm{nM})$ to determine if cytokine secretion was affected. FTY720 treatment did not affect secretion of either IFN- $\gamma$ or TNF- $\alpha$ compared to vehicletreated cultures (Figure 2C). Finally, FTY720 treatment of CD8+ T cells did not affect lytic activity compared to controls (Figure 2D). These findings argue that FTY720 treatment does not dampen anti-viral $\mathrm{T}$ cell effector functions.
FTY720 treatment impairs T cell trafficking into the CNS We next determined if FTY720 affected S1P1 expression on circulating lymphocytes in JHMV-infected mice. Administration of FTY720 reduced S1P1 on circulating CD3+ lymphocytes $(P<0.001)$ compared to vehicle-treated controls at day 7 p.i. (Figure 3A,B). Examination of $\mathrm{T}$ cell infiltration into the CNS of FTY720-treated mice infected with virus indicated reduced frequency of CD4+ T cells $(P<0.05)$ at day 7 p.i. although $\mathrm{CD} 4+\mathrm{T}$ cell trafficking was

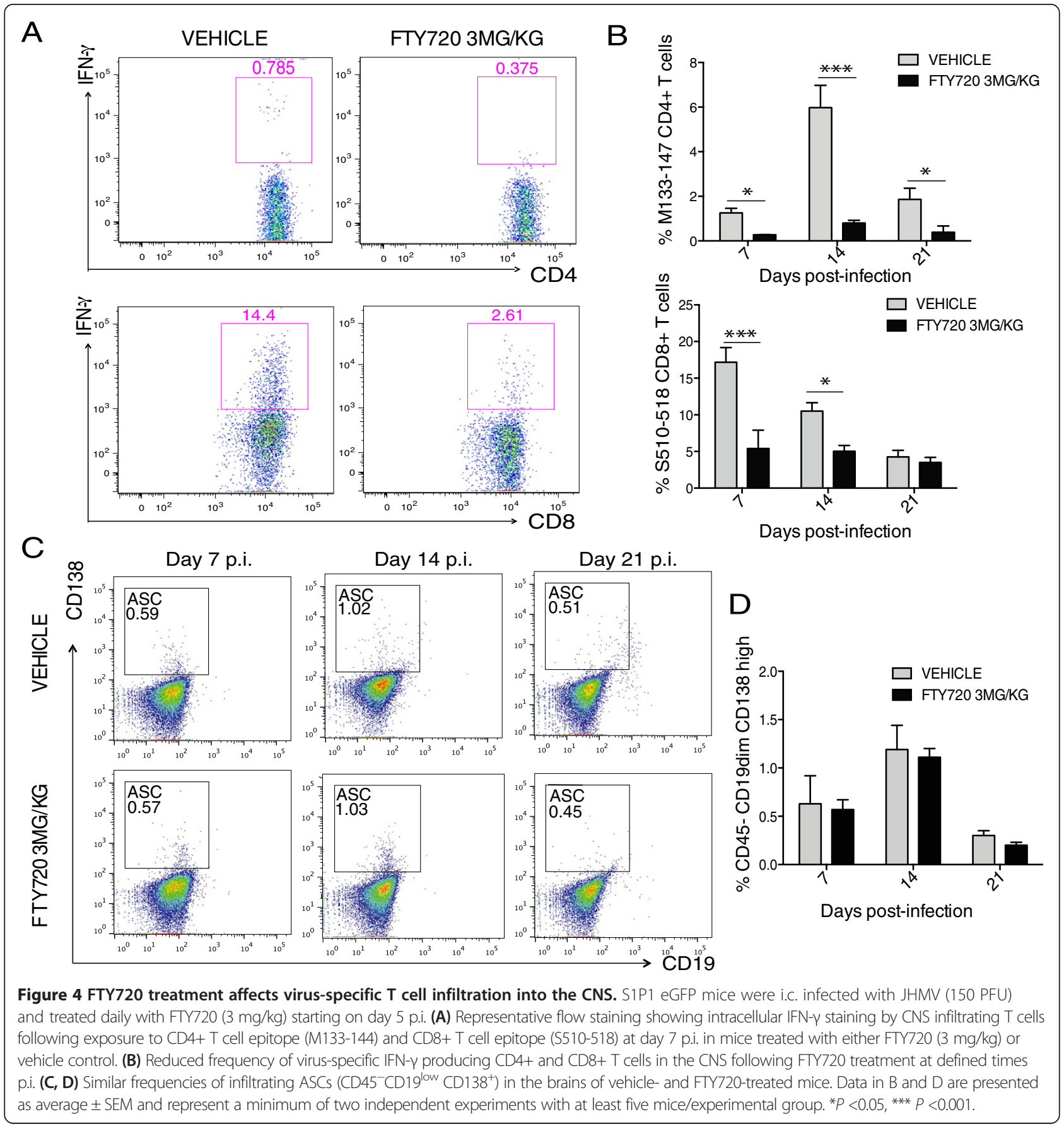


not affected at days 14 and 21 p.i (Figure 3C,D). Further, FTY720 treatment did not affect CD8+ T cell infiltration into the CNS at days 7, 14 and 21 p.i. (Figure 3C,E).

Infiltration of virus-specific CD4+ and CD8+ T cells, as determined by intracellular IFN- $\gamma$ staining in response to treatment with immunodominant $\mathrm{CD} 4+$ and $\mathrm{CD} 8+$ viral epitopes [42,43], was diminished at days $7(P<0.01)$ and $14(P<0.05)$ following FTY720 treatment in comparison to vehicle-treated mice (Figure $4 \mathrm{~A}, \mathrm{~B}$ ). By day 21 p.i., infiltration of virus-specific CD4+ $\mathrm{T}$ cells, but not virus-specific $\mathrm{CD} 8+\mathrm{T}$ cells, was also reduced $(P<0.05)$ in FTY720-treated mice compared to control animals (Figure 4B). Infiltration of antibody secreting cells (ASCs) (CD45 ${ }^{-} \mathrm{CD} 19^{\text {low }} \mathrm{CD} 138+$ ) into the CNS of JHMV-infected mice was not reduced at either days 7,14 or 21 p.i. following FTY720 treatment compared to control mice (Figure 4C,D). These findings indicate that administration of FTY720 negatively impacts recruitment of T lymphocytes into the CNS in response to JHMV infection.

\section{FTY720 restricts lymphocyte egress from draining cervical} lymph nodes

As an S1P1 functional antagonist, FTY720 disrupts the S1P gradient in lymph nodes thereby trapping lymphocytes $[4,5]$. To establish if this occurs during ongoing neuroinflammation in response to infection with neurotropic JHMV, draining cervical lymph nodes (dCLNs) were examined at defined times p.i. following treatment with FTY720. Administration of FTY720 revealed an increase in size and weight of dCLNs in FTY720-treated mice compared to control mice at day 7 p.i. (Figure 5A,B). Immunophenotyping lymphocytes in dCLNs by flow cytometry revealed an increased frequency of B220+ B cells (Figure 5C), CD4+ T cells (Figure 5D) and CD8+ T cells (Figure 5E) in mice treated with FTY720 compared to controls, indicating increased retention of lymphocytes in lymphatic tissue in response to S1P antagonism.

\section{FTY720 diminishes the severity of demyelination in JHMV-infected mice}

To investigate the potential effect of FTY720 on spinal cord neuroinflammation and demyelination in JHMVinfected mice, an evaluation of the severity of white matter damage was performed at day 21 p.i. Spinal cord inflammation was reduced $(P<0.05)$ within spinal cords at day 21 p.i. as assessed by H\&E staining (Figure 6A,B). Moreover, LFB staining revealed a significant $(P<0.05)$ reduction in demyelination in response to FTY720 treatment compared to control mice (Figure 6A,B). Immunophenotyping of infiltrating lymphocytes in the spinal cord day 21 p.i. revealed a decrease in CD8+ T cell as well as CD4+ T cell percentages $(P<0.05)$ in FTY720-treated mice compared to vehicle-treated mice (Figure $6 \mathrm{C}, \mathrm{D}$ ). This suggests that reduction in the severity of demyelination
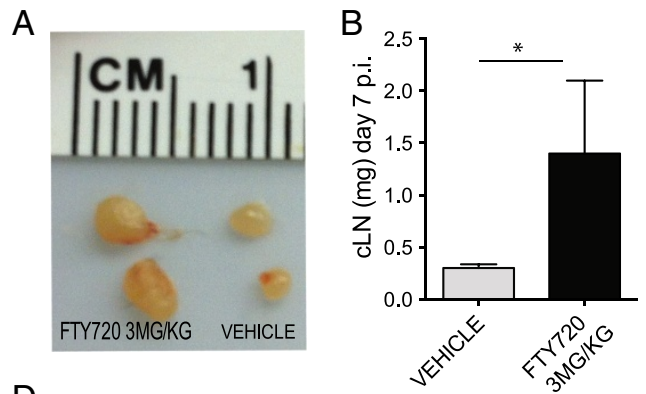

$\mathrm{D}$

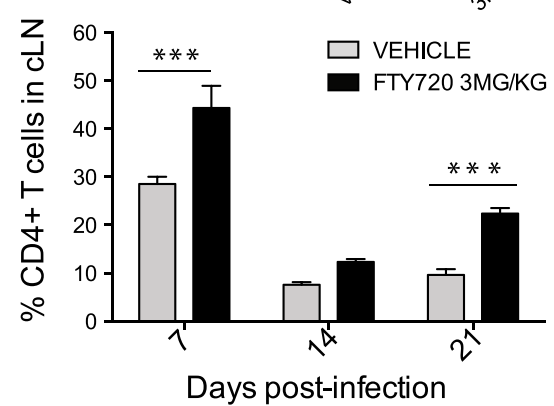

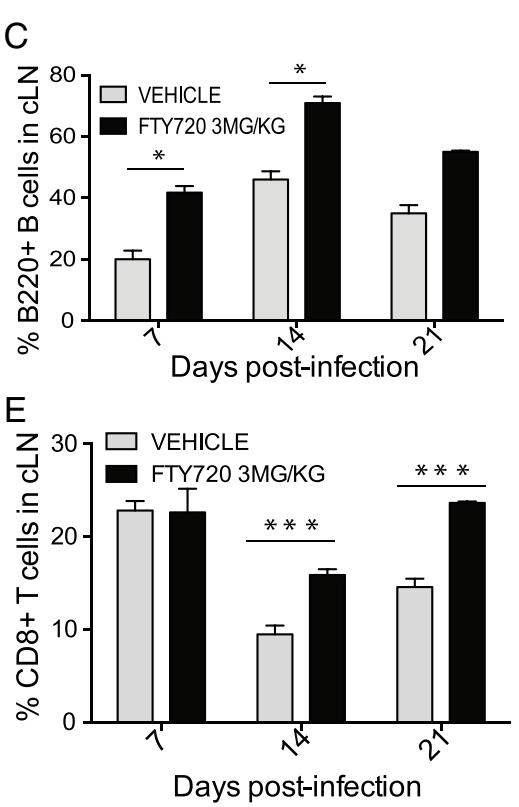

Figure 5 Increased lymphocyte retention in dCLNs following FTY720 treatment of JHMV-infected mice. S1P1 eGFP mice were i.c. infected with JHMV (150 PFU) and treated daily with FTY720 (3 mg/kg) beginning on day 5 p.i. On days 7, 14 and 21 p.i., dCLNs were isolated to examine size, weight and immunophenotype lymphocyte population by flow cytometry. (A) Representative image depicting the increase in size of dCLNs obtained from FTY720-treated mice compared to vehicle control-treated mice at day 7 p.i. (B) Average weight of dCLNs increased in response to FTY720 treatment compared to vehicle $(P<0.05)$. Treatment with FTY720 resulted in increased retention of B220+ B cells (C), CD4+ T cells (D) and CD8+ T cells $(\mathbf{E})$ at defined times p.i. Data in panels $B$ to $E$ represent average \pm SEM obtained from two or three independent experiments with a minimum of four mice/group. ${ }^{*} P<0.05$, ${ }^{* *} P<0.001$. cLN, cervical lymph node. $d C L N$, draining cervical lymph node. 

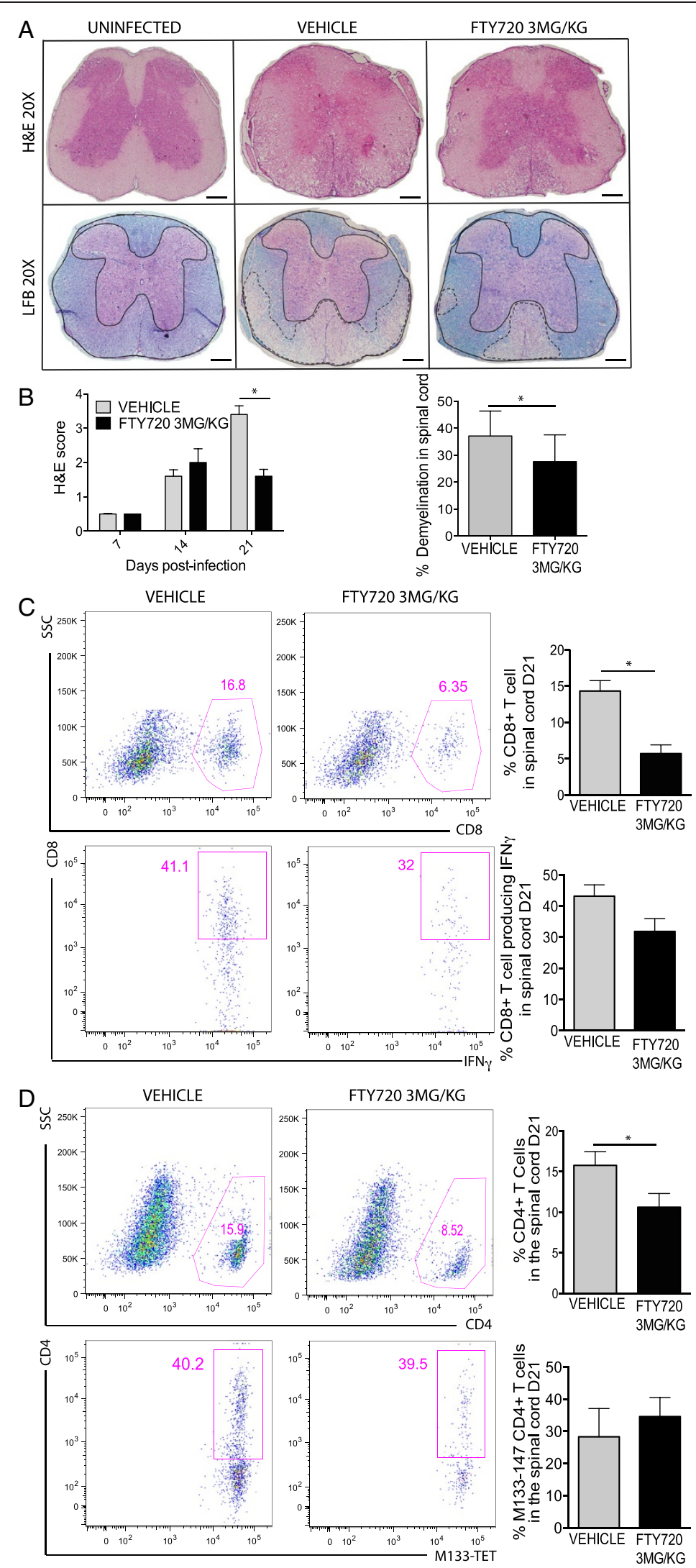

Figure 6 (See legend on next page.) 
following FTY720 treatment is the result of a decrease in infiltration of inflammatory cells into the spinal cord.

\section{Discussion}

FTY720/fingolimod was the first oral treatment approved by the FDA for relapsing forms of MS $[10,54,55]$. Numerous clinical trials highlighted FTY720 efficacy as demonstrated by benefits for relapses and magnetic resonance imaging (MRI) lesions [9]. In addition, disability progression was impacted and there was a reduction in brain volume loss in MS patients in response to treatment $[56,57]$. Although the mechanisms by which FTY720 exerts a protective effect are not defined, it is generally accepted that the main mode of action is via an immunomodulatory effect by restricting lymphocyte circulation from lymph nodes to the CNS. Dampened accumulation of activated lymphocytes in the CNS in response to FTY720 treatment most likely accounts for reduced MRI lesion activity and this is supported in preclinical animal studies using EAE $[14,15,58]$. Whether the reduction in brain volume loss is also dependent upon reduced neuroinflammation or a direct neuroprotective effect has not been determined. Recent evidence argues that FTY720 exerts a neuroprotective effect as animals in which the receptor S1P1 is selectively ablated on astrocytes are resistant to the protective effects of FTY720 treatment following induction of EAE, although S1P1 remains expressed on circulating lymphocytes [12,59]. However, more recent studies by Cahalan et al. indicate that S1P1 antagonism reverses EAE without acting on S1P1 expressed within the CNS, supporting the notion that restricting lymphocyte egress from lymphatic tissue is sufficient to diminish disease severity [60]. Moreover, the maintenance of egress inhibition is not required for efficacy in EAE if brain levels of agonist are maintained in the steady state. Full efficacy is achieved with inhibition of egress for only $30 \%$ of the 24-h dosing interval with complete recovery of circulating lymphocytes. Direct effects within the CNS were demonstrated for neurons, astrocytes and the blood-brainbarrier, and on the inhibition of migration of lymphocytes from perivascular cuffs into the parenchyma [61].

We chose a model of viral-induced neurologic disease to determine if FTY720 treatment affects host defense and disease progression. Our rationale for using the JHMV model of acute encephalomyelitis and demyelination to assess the therapeutic benefit of FTY720 is based on the fact that the overwhelming majority of preclinical animal models examining the mode of action for FTY720 is derived from EAE, yet how this drug affects models of viral-induced CNS disease are not well characterized. In addition, viral infections have long been thought to have a role in either initiating or contributing to relapse in MS patients [28-34,62]. How treatment with FTY720 influences outcomes in response to viral infection is highlighted by recent clinical studies detailing the emergence of herpes zoster and associated neurologic complications in MS patients during FTY720 treatment $[63,64]$. These findings suggest immunosuppression may arise in response to FTY720 treatment resulting in re-emergence of persistent viruses. However, administration of FTY720 to mice infected with lymphocytic choriomeningitis did not ameliorate persistence, indicating that the outcome may be dictated, in part, by the virus and sites of infection [65]. Related to these observations are studies demonstrating that treatment with FTY720 or other S1P1 agonists dramatically affects cytokine production and disease outcome in mice infected with influenza virus, indicating the immunomodulatory effects of such treatment [66]. With regards to viral models of demyelination, Pachner and colleagues [67] demonstrated that administration of FTY720 had no effect on clinical disease progression or viral load within the CNS using Theiler's murine encephalomyelitis virus model of demyelination. These findings are in contrast with findings using EAE, in which FTY720 treatment reduced clinical disease severity accompanied by limited infiltration of immune cells into the CNS $[13-15,68,69]$.

Our findings show that FTY720 treatment for JHMVinfected mice increased clinical disease severity as well as mortality. Importantly, these findings correlate with impaired ability to control viral replication within the CNS. The muted host defense resulting from S1P receptor antagonism was not the result of dampened anti-viral $\mathrm{T}$ cell effector responses, e.g. proliferation, cytokine secretion or CTL activity, but rather an inability of lymphocytes to migrate and accumulate within the CNS effectively. Indeed, administration of FTY720 increased retention of $\mathrm{T}$ and $\mathrm{B}$ lymphocytes within the dCLNs, consistent with earlier reports that blocking S1P receptors disrupts lymphocyte egress from secondary lymphatic tissue [70,71]. Although viral titers were elevated within 
the CNS of FTY720-treated mice, surviving mice were able to reduce the amount of virus below the level of detection and this lasted to day 28 p.i., arguing that viral recrudescence does not occur in this model.

Administration of FTY720 either prophylactically or therapeutically in models of EAE results in reduced lymphocyte penetration into the CNS, which is associated with a reduction in the severity of demyelination $[14,15,58]$. Similarly, our results show that the effects of FTY720 treatment on CNS inflammation in JHMVinfected mice correlates with a reduction in the severity of spinal cord demyelination. Examination of the posterior funiculus and lateral white matter columns of FTY720treated mice compared to controls showed an overall reduction in lesion size, demonstrating that in addition to reducing myelin damage in EAE, FTY720 is also effective in limiting the spread of demyelination in a viral model of MS. FTY720 has also been shown to prevent axonal damage in EAE [58]. FTY720 in combination with other drugs in EAE or cerebellar slice cultures has been shown to augment remyelination, supporting a regenerative potential [72,73]. These findings support that FTY720 may act directly upon resident cells of the CNS promoting protection and repair. This is supported by elegant studies from Chun and colleagues [12] that showed attenuation in EAE and a loss of FTY720 efficacy in conditional null mouse mutants lacking S1P1 in astrocytes. These findings highlight that FTY720-mediated protection in EAE occurs via a nonimmunological mechanism and suggest that targeting S1P signaling within the CNS may be relevant for recovery for both EAE and MS patients. Whether extensive axonal sparing and/or remyelination occurs following FTY720 administration to JHMV-infected mice is not known at this time and is an area of ongoing work.

\section{Conclusions}

In this study we demonstrate that FTY720 mutes effective anti-viral immune responses by preventing migration and accumulation of virus-specific T cells within the CNS during acute viral-induced encephalomyelitis. FTY720 treatment reduces the severity of neuroinflammatorymediated demyelination by limiting $\mathrm{T}$ cell egress from lymph nodes thereby reducing lymphocyte infiltration into the CNS. FTY720 did not alter anti-viral effects of T cells, e.g. cytokine secretion or cytolytic activity.

\footnotetext{
Abbreviations

ASC: antibody secreting cell; BSA: bovine serum albumin; CFSE: carboxyfluorescein succinimidyl ester; CNS: central nervous system; CTL: cytotoxic T lymphocyte; dCLN: draining cervical lymph node; EAE: experimental autoimmune encephalomyelitis; ELISA: enzyme-linked immunosorbent assay; FDA: Food and Drug Administration; FTY720P: FTY720-phosphate; H\&E: hematoxylin and eosin; i.c.: intra-cerebral; IFN-ү: interferon-gamma; i.p.: intra-peritoneal; JHMV: JHM strain of mouse hepatitis virus; LDH: lactate dehydrogenase; LFB: luxol fast blue; MHV: mouse hepatitis virus; MRI: magnetic resonance imaging; MS: multiple sclerosis;
}

PFU: plaque forming units; p.i.: post-infection; S1P: sphingosine-1-phosphate; SEM: standard error of the mean; TNF-a: tumor necrosis factor alpha.

\section{Competing interests}

$C A B$ and TEL declare they have no competing interests. HR is a cofounder and member of the scientific advisory board for Receptos, Inc.

\section{Authors' contributions}

$\mathrm{CAB}$ designed and conducted the experiments, analyzed and interpreted the data, and wrote the manuscript. TEL designed the research, analyzed and interpreted the data, and wrote the manuscript. HR assisted in data interpretation and wrote the manuscript. All authors read and approved the final manuscript.

\section{Acknowledgments}

The authors wish to acknowledge the excellent technical assistance of Edna Hingco and Colleen Worne. This work was supported, in part, by National Institutes of Health grant R01 NS041249 and generous support from the Hausman Family Foundation and Dawn Beattie.

\section{Author details}

'Department of Molecular Biology and Biochemistry, University of California, Irvine, California 92697-3900, USA. ${ }^{2}$ Department of Chemical Physiology, The Scripps Research Institute, La Jolla, California 92037, USA. ${ }^{3}$ Department of Pathology, Division of Microbiology \& Immunology, University of Utah School of Medicine, Salt Lake City, Utah 84112, USA.

Received: 29 May 2014 Accepted: 27 July 2014

Published: 20 August 2014

\section{References}

1. Compston A, Coles A: Multiple sclerosis. Lancet 2002, 359:1221-1231.

2. Hauser SL, Chan JR, Oksenberg JR: Multiple sclerosis: prospects and promise. Ann Neurol 2013, 74:317-327.

3. Cohen JA, Chun J: Mechanisms of fingolimod's efficacy and adverse effects in multiple sclerosis. Ann Neurol 2011, 69:759-777.

4. Ingwersen J, Aktas O, Kuery P, Kieseier B, Boyko A, Hartung HP: Fingolimod in multiple sclerosis: mechanisms of action and clinical efficacy. Clin Immunol 2012, 142:15-24.

5. Mehling M, Johnson TA, Antel J, Kappos L, Bar-Or A: Clinical immunology of the sphingosine 1-phosphate receptor modulator fingolimod (FTY720) in multiple sclerosis. Neurology 2011, 76:S20-S27.

6. O'Connor P, Comi G, Montalban X, Antel J, Radue EW, de Vera A, Pohlmann H, Kappos L, Group FDS: Oral fingolimod (FTY720) in multiple sclerosis: two-year results of a phase II extension study. Neurology 2009, 72:73-79.

7. Aktas $\mathrm{O}$, Kury P, Kieseier B, Hartung HP: Fingolimod is a potential novel therapy for multiple sclerosis. Nat Rev Neurol 2010, 6:373-382.

8. Deogracias R, Yazdani M, Dekkers MP, Guy J, lonescu MC, Vogt KE, Barde YA: Fingolimod, a sphingosine-1 phosphate receptor modulator, increases BDNF levels and improves symptoms of a mouse model of Rett syndrome. Proc Natl Acad Sci USA 2012, 109:14230-14235.

9. Willis MA, Cohen JA: Fingolimod therapy for multiple sclerosis. Semin Neurol 2013, 33:37-44.

10. Brinkmann V, Billich A, Baumruker T, Heining P, Schmouder R, Francis G, Aradhye S, Burtin P: Fingolimod (FTY720): discovery and development of an oral drug to treat multiple sclerosis. Nat Rev Drug Discov 2010, 9:883-897.

11. Mandala S, Hajdu R, Bergstrom J, Quackenbush E, Xie J, Milligan J, Thornton R, Shei GJ, Card D, Keohane C, Rosenbach M, Hale J, Lynch CL, Rupprecht K, Parsons W, Rosen H: Alteration of lymphocyte trafficking by sphingosine-1phosphate receptor agonists. Science 2002, 296:346-349.

12. Choi JW, Gardell SE, Herr DR, Rivera R, Lee CW, Noguchi K, Teo ST, Yung YC, Lu M, Kennedy G, Chun J: FTY720 (fingolimod) efficacy in an animal model of multiple sclerosis requires astrocyte sphingosine 1-phosphate receptor 1 (S1P1) modulation. Proc Natl Acad Sci USA 2011, 108:751-756.

13. Fujino M, Funeshima N, Kitazawa Y, Kimura H, Amemiya H, Suzuki S, Li XK: Amelioration of experimental autoimmune encephalomyelitis in Lewis rats by FTY720 treatment. J Pharmacol Exp Ther 2003, 305:70-77.

14. Kataoka H, Sugahara K, Shimano K, Teshima K, Koyama M, Fukunari A, Chiba K: FTY720, sphingosine 1-phosphate receptor modulator, ameliorates experimental autoimmune encephalomyelitis by inhibition of $\mathrm{T}$ cell infiltration. Cell Mol Immunol 2005, 2:439-448. 
15. Webb M, Tham CS, Lin FF, Lariosa-Willingham K, Yu N, Hale J, Mandala S, Chun J, Rao TS: Sphingosine 1-phosphate receptor agonists attenuate relapsing-remitting experimental autoimmune encephalitis in SJL mice. J Neuroimmunol 2004, 153:108-121.

16. Lane TE, Liu MT, Chen BP, Asensio VC, Samawi RM, Paoletti AD, Campbell IL, Kunkel SL, Fox HS, Buchmeier MJ: A central role for $\mathrm{CD}^{+} \mathrm{T}$ cells and RANTES in virus-induced central nervous system inflammation and demyelination. J Virol 2000, 74:1415-1424.

17. Wu GF, Dandekar AA, Pewe L, Perlman S: CD4 and CD8 T cells have redundant but not identical roles in virus-induced demyelination. J Immunol 2000, 165:2278-2286.

18. Wu GF, Perlman S: Macrophage infiltration, but not apoptosis, is correlated with immune-mediated demyelination following murine infection with a neurotropic coronavirus. J Virol 1999, 73:8771-8780.

19. Herndon RM, Griffin DE, McCormick U, Weiner LP: Mouse hepatitis virus-induced recurrent demyelination. A preliminary report. Arch Neurol 1975, 32:32-35.

20. Weiner LP: Pathogenesis of demyelination induced by a mouse hepatitis. Arch Neurol 1973, 28:298-303.

21. Lane TE, Buchmeier MJ: Murine coronavirus infection: a paradigm for virus-induced demyelinating disease. Trends Microbiol 1997, 5:9-14

22. Pender MP, Csurhes PA, Smith C, Beagley L, Hooper KD, Raj M, Coulthard A, Burrows SR, Khanna R: Epstein-Barr virus-specific adoptive immunotherapy for progressive multiple sclerosis. Mult Scler 2014, doi:10.1177/1352458514521888.

23. Mameli G, Cossu D, Cocco E, Masala S, Frau J, Marrosu MG, Sechi LA: EBNA-1 IgG titers in Sardinian multiple sclerosis patients and controls. J Neuroimmunol 2013, 264:120-122.

24. Strautins K, Tschochner M, James I, Choo L, Dunn D, Pedrini M, Kermode A, Carroll W, Nolan D: Combining HLA-DR risk alleles and anti-Epstein-Barr virus antibody profiles to stratify multiple sclerosis risk. Mult Scler 2014, 20:286-294.

25. Virtanen JO, Wohler J, Fenton K, Reich DS, Jacobson S: Oligoclonal bands in multiple sclerosis reactive against two herpesviruses and association with magnetic resonance imaging findings. Mult Scler 2014, 20:27-34.

26. Libbey JE, Cusick MF, Fujinami RS: Role of pathogens in multiple sclerosis. Int Rev Immunol 2013, 33(4):266-283.

27. Cusick MF, Libbey JE, Fujinami RS: Multiple sclerosis: autoimmunity and viruses. Curr Opin Rheumatol 2013, 25:496-501.

28. Friedman JE, Lyons MJ, Cu G, Ablashl DV, Whitman JE, Edgar M, Koskiniemi M, Vaheri A, Zabriskie JB: The association of the human herpesvirus- 6 and MS. Mult Scler 1999, 5:355-362.

29. Lincoln JA, Hankiewicz K, Cook SD: Could Epstein-Barr virus or canine distemper virus cause multiple sclerosis? Neurol Clin 2008, 26:699-715. viii.

30. Lipton HL, Liang Z, Hertzler S, Son KN: A specific viral cause of multiple sclerosis: one virus, one disease. Ann Neurol 2007, 61:514-523.

31. McCoy L, Tsunoda I, Fujinami RS: Multiple sclerosis and virus induced immune responses: autoimmunity can be primed by molecular mimicry and augmented by bystander activation. Autoimmunity 2006, 39:9-19.

32. Olson JK, Ercolini AM, Miller SD: A virus-induced molecular mimicry model of multiple sclerosis. Curr Top Microbiol Immunol 2005, 296:39-53.

33. Pugliatti M, Harbo HF, Holmoy T, Kampman MT, Myhr KM, Riise T, Wolfson C: Environmental risk factors in multiple sclerosis. Acta Neurol Scand Suppl 2008, 188:34-40

34. Tompkins SM, Fuller KG, Miller SD: Theiler's virus-mediated autoimmunity: local presentation of CNS antigens and epitope spreading. Ann NY Acad Sci 2002, 958:26-38.

35. Tsunoda I, Fujinami RS: Inside-out versus outside-in models for virus induced demyelination: axonal damage triggering demyelination. Springer Semin Immunopathol 2002, 24:105-125

36. Cahalan SM, Gonzalez-Cabrera PJ, Sarkisyan G, Nguyen N, Schaeffer MT, Huang L, Yeager A, Clemons B, Scott F, Rosen H: Actions of a picomolar short-acting S1P(1) agonist in S1P(1)-eGFP knock-in mice. Nat Chem Biol 2011, 7:254-256.

37. Carbajal KS, Schaumburg C, Strieter R, Kane J, Lane TE: Migration of engrafted neural stem cells is mediated by CXCL12 signaling through CXCR4 in a viral model of multiple sclerosis. Proc Natl Acad Sci USA 2010, 107:11068-11073.

38. Lane TE, Asensio VC, Yu N, Paoletti AD, Campbell IL, Buchmeier MJ: Dynamic regulation of $\alpha$ - and $\beta$-chemokine expression in the central nervous system during mouse hepatitis virus-induced demyelinating disease. J Immunol 1998, 160:970-978.
39. Stiles LN, Hardison JL, Schaumburg CS, Whitman LM, Lane TE: T cell antiviral effector function is not dependent on CXCL10 following murine coronavirus infection. J Immunol 2006, 177:8372-8380.

40. Stiles LN, Hosking MP, Edwards RA, Strieter RM, Lane TE: Differential roles for CXCR3 in CD4+ and CD8+ T cell trafficking following viral infection of the CNS. Eur J Immunol 2006, 36:613-622.

41. Stiles LN, Liu MT, Kane JAC, Lane TE: CXCL10 and trafficking of virus-specific T cells during coronavirus demyelination. Autoimmunity 2009, 42(6):484-491.

42. Bergmann CC, Yao Q, Lin M, Stohlman SA: The JHM strain of mouse hepatitis virus induces a spike protein-specific Db-restricted cytotoxic $T$ cell response. J Gen Virol 1996, 77(Pt 2):315-325.

43. Xue S, Jaszewski A, Perlman S: Identification of a CD4+ T cell epitope within the M protein of a neurotropic coronavirus. Virology 1995, 208:173-179.

44. Glass WG, Hickey MJ, Hardison JL, Liu MT, Manning JE, Lane TE: Antibody targeting of the CC chemokine ligand 5 results in diminished leukocyte infiltration into the central nervous system and reduced neurologic disease in a viral model of multiple sclerosis. J Immunol 2004, 172:4018-4025.

45. Glass WG, Lane TE: Functional analysis of the CC chemokine receptor 5 (CCR5) on virus-specific CD8+ T cells following coronavirus infection of the central nervous system. Virology 2003, 312:407-414.

46. Totoiu MO, Nistor GI, Lane TE, Keirstead HS: Remyelination, axonal sparing, and locomotor recovery following transplantation of glial-committed progenitor cells into the MHV model of multiple sclerosis. Exp Neurol 2004, 187:254-265.

47. Bergmann CC, Lane TE, StohIman SA: Coronavirus infection of the central nervous system: host-virus stand-off. Nat Rev Microbio/ 2006, 4:121-132.

48. Gonzalez JM, Bergmann CC, Ramakrishna C, Hinton DR, Atkinson R, Hoskin J, Macklin WB, Stohlman SA: Inhibition of interferon- $\gamma$ signaling in oligodendroglia delays coronavirus clearance without altering demyelination. Am J Pathol 2006, 168:796-804

49. Marten NW, Stohlman SA, Bergmann CC: MHV infection of the CNS: mechanisms of immune-mediated control. Viral Immunol 2001, 14:1-18.

50. Parra B, Hinton DR, Marten NW, Bergmann CC, Lin MT, Yang CS, Stohlman $S A$ : IFN- $\gamma$ is required for viral clearance from central nervous system oligodendroglia. J Immunol 1999, 162:1641-1647.

51. Ramakrishna C, Bergmann CC, Atkinson R, Stohlman SA: Control of central nervous system viral persistence by neutralizing antibody. J Virol 2003 77:4670-4678.

52. Ramakrishna C, Stohlman SA, Atkinson RD, Shlomchik MJ, Bergmann CC: Mechanisms of central nervous system viral persistence: the critical role of antibody and B cells. J Immunol 2002, 168:1204-1211.

53. Stohlman SA, Bergmann CC, Lin MT, Cua DJ, Hinton DR: CTL effector function within the central nervous system requires CD4+ T cells. J Immunol 1998, 160:2896-2904.

54. Strader CR, Pearce CJ, Oberlies NH: Fingolimod (FTY720): a recently approved multiple sclerosis drug based on a fungal secondary metabolite. J Nat Prod 2011, 74:900-907.

55. Chun J, Brinkmann V: A mechanistically novel, first oral therapy for multiple sclerosis: the development of fingolimod (FTY720, Gilenya). Discov Med 2011, 12:213-228.

56. Radue EW, O'Connor P, Polman CH, Hohlfeld R, Calabresi P, Selmaj $\mathrm{K}$, Mueller-Lenke N, Agoropoulou C, Holdbrook F, de Vera A, Zhang-Auberson L, Francis $G$, Burtin $P$, Kappos $L$ : Impact of fingolimod therapy on magnetic resonance imaging outcomes in patients with multiple sclerosis. Arch Neurol 2012, 69:1259-1269.

57. Cohen JA, Barkhof F, Comi G, Izquierdo G, Khatri B, Montalban X, Pelletier J, Eckert B, Haring DA, Francis G: Fingolimod versus intramuscular interferon in patient subgroups from TRANSFORMS. J Neurol 2013, 260:2023-2032.

58. Wang X, Brieland JK, Kim JH, Chen YJ, O'Neal J, O'Neil SP, Tu TW, Trinkaus K, Song SK: Diffusion tensor imaging detects treatment effects of FTY720 in experimental autoimmune encephalomyelitis mice. NMR Biomed 2013, 26:1742-1750.

59. Groves A, Kihara Y, Chun J: Fingolimod: direct CNS effects of sphingosine 1-phosphate (S1P) receptor modulation and implications in multiple sclerosis therapy. J Neurol Sci 2013, 328:9-18.

60. Cahalan SM, Gonzalez-Cabrera PJ, Nguyen N, Guerrero M, Cisar EA, Leaf NB, Brown SJ, Roberts E, Rosen H: Sphingosine 1-phosphate receptor 1 (S1P(1)) upregulation and amelioration of experimental autoimmune encephalomyelitis by an S1P(1) antagonist. Mol Pharmacol 2013, 83:316-321.

61. Gonzalez-Cabrera PJ, Cahalan SM, Nguyen N, Sarkisyan G, Leaf NB, Cameron MD, Kago T, Rosen H: S1P(1) receptor modulation with cyclical recovery from 
lymphopenia ameliorates mouse model of multiple sclerosis. Mol Pharmacol 2012, 81:166-174

62. Johnson RT: The virology of demyelinating diseases. Ann Neurol 1994, 36(Suppl):S54-S60.

63. Gross CM, Baumgartner A, Rauer S, Stich O: Multiple sclerosis rebound following herpes zoster infection and suspension of fingolimod. Neurology 2012, 79:2006-2007.

64. Ratchford JN, Costello K, Reich DS, Calabresi PA: Varicella-zoster virus encephalitis and vasculopathy in a patient treated with fingolimod. Neurology 2012, 79:2002-2004.

65. Walsh KB, Marsolais D, Welch MJ, Rosen H, Oldstone MB: Treatment with a sphingosine analog does not alter the outcome of a persistent virus infection. Virology 2010, 397:260-269.

66. Walsh KB, Teijaro JR, Wilker PR, Jatzek A, Fremgen DM, Das SC, Watanabe T, Hatta M, Shinya K, Suresh M, Kawaoka Y, Rosen H, Oldstone MB: Suppression of cytokine storm with a sphingosine analog provides protection against pathogenic influenza virus. Proc Natl Acad Sci USA 2011, 108:12018-12023.

67. Li L, Matsumoto M, Seabrook TJ, Cojean C, Brinkman V, Pachner AR: The effect of FTY720 in the Theiler's virus model of multiple sclerosis. J Neurol Sci 2011, 308:41-48.

68. Balatoni B, Storch MK, Swoboda EM, Schonborn V, Koziel A, Lambrou GN, Hiestand PC, Weissert R, Foster CA: FTY720 sustains and restores neuronal function in the DA rat model of MOG-induced experimental autoimmune encephalomyelitis. Brain Res Bull 2007, 74:307-316.

69. Foster CA, Mechtcheriakova D, Storch MK, Balatoni B, Howard LM, Bornancin F, Wlachos A, Sobanov J, Kinnunen A, Baumruker T: FTY720 rescue therapy in the dark agouti rat model of experimental autoimmune encephalomyelitis: expression of central nervous system genes and reversal of blood-brain-barrier damage. Brain Pathol 2009, 19:254-266.

70. Cyster JG, Schwab SR: Sphingosine-1-phosphate and lymphocyte egress from lymphoid organs. Annu Rev Immunol 2012, 30:69-94.

71. Matloubian M, Lo CG, Cinamon G, Lesneski MJ, Xu Y, Brinkmann V, Allende ML, Proia RL, Cyster JG: Lymphocyte egress from thymus and peripheral lymphoid organs is dependent on S1P receptor 1. Nature 2004, 427:355-360

72. Deshmukh VA, Tardif V, Lyssiotis CA, Green CC, Kerman B, Kim HJ, Padmanabhan K, Swoboda JG, Ahmad I, Kondo T, Gage FH, Theofilopoulos AN, Lawson BR, Schultz PG, Lairson LL: A regenerative approach to the treatment of multiple sclerosis. Nature 2013, 502:327-332.

73. Miron VE, Ludwin SK, Darlington PJ, Jarjour AA, Soliven B, Kennedy TE, Antel JP: Fingolimod (FTY720) enhances remyelination following demyelination of organotypic cerebellar slices. Am J Pathol 2010, 176:2682-2694.

doi:10.1186/s12974-014-0138-y

Cite this article as: Blanc et al:: FTY720 (fingolimod) modulates the severity of viral-induced encephalomyelitis and demyelination. Journal of Neuroinflammation 2014 11:138

\section{Submit your next manuscript to BioMed Central and take full advantage of:}

- Convenient online submission

- Thorough peer review

- No space constraints or color figure charges

- Immediate publication on acceptance

- Inclusion in PubMed, CAS, Scopus and Google Scholar

- Research which is freely available for redistribution 